\title{
The new forestry building
}

Adequate accommodation for the Faculty of Forestry has finally materialized after many years of waiting. One who observes the quality of the architectural design from the outside of the new building and inspects its provisions for the work in hand from the inside, may well conclude that the waiting was worth while. The building is Georgian in style and is the work of Darling and Pearson, architects. It is constructed of red brick and stone. The basal portion of the walls is gray limestone. The corners are reinforced by limestone quoins and the window lintels of stone are supported by fluted jambs. A string course of limestone runs around the building above the second floor windows. The building terminates above the stone cornice in a balustraded parapet. The front entrance is to be especially noted for its dignity and simple beauty...

The rooms are in units of 21 feet to the central corridor, which is eight feet wide, and are 14 feet to the ceiling. The building contains three lecture rooms, three laboratories and four staff rooms. Each lecture room accommodates 31 students. The laboratories are 40 feet long and contain 34 working places. Each laboratory carries with it en suite its supply and preparation room.

The ground floor contains an exhibition room, which, when completed, will contain for teaching purposes, specimens of leaves, flowers and fruits of the native Canadian trees. Another section will be devoted to a corresponding exhibit of foreign species competing in the lumber trade with Canadian woods, while a third will have reference to introduced trees used in park and street planting. A portion of the room will be devoted to a display of uniform boards, two feet long, of all the woods encountered by the building trades of the country, especially those of eastern Canada.

The ground floor contains a combination library and reading room and a stack room. The library of the Faculty, consisting of some 2,000 bound volumes and 6,000 pamphlets, will be for the first time conveniently accessible, for in the old building portions of it were stored in various places in boxes and cupboards...

The second floor is given over entirely to the study of Dendrology, or in other words, to the study of trees, their form and structure. The supply room of the Dendrology laboratory contains some 1,500 specimens of tree leaves, flowers and fruits preserved in fluids, and a corresponding number in dry condition. Besides these there are over 5,000 specimens of woods in convenient form for classroom study. A great deal of this material was in storage in the old quarters.

The top floor contains two laboratories, those of Mensuration and Silviculture, located there because of the necessity of overhead light in carrying out their purposes. Mensuration, as the name suggests, is concerned with the measurement of trees and forests from the standpoint of the cubic contents. The study also involves a consideration of the rate of volume growth and accretion. The form of trees, the rate of growth of single trees and stands, the relation between expenditures and crop values are expressed now-a-days by means of curves, charts and graphs. This will be the first time the Faculty has had a room with proper skylight for doing such work...

Before one can produce or care for a forest, he must understand the characteristics of the individuals composing it and that is the purpose of the Silviculture laboratory. Tree seeds and their germinating capacity under various conditions are studied, as well as the influence of light and humidity, on the growth of the seedlings. Next the attention of the laboratory work is directed to the study of soils, which influence tree growth more than any other factor. The Silviculture laboratory with its skylight and four large windows is admirably planned for work of this kind.

The new building will give the Faculty of Forestry a status it never enjoyed before, and an opportunity to grow, not in numbers necessarily, but in service to the University, the community, the Province and to the profession at large. The first development will be along the lines of extension courses to those concerned with the wood-using industries and to those who work in various capacities in the forest. Then will come an opportunity and facilities for graduate students to work out some of the many problems that confront the profession.

The above is from a description by Dean C. D. Howe of the new Faculty of Forestry building at the University of Toronto and appeared in the second issue of The Forestry Chronicle.

Fifty years later in the National Statement by the schools of forestry at Canadian universities comes the comment "we are struggling to discharge our responsibilities under crowded conditions and in poorly-equipped teaching facilities and research laboratories. Students are also voicing dissatisfaction with the inadequate physical plant..." Plus ça change, plus c'est la même chose.

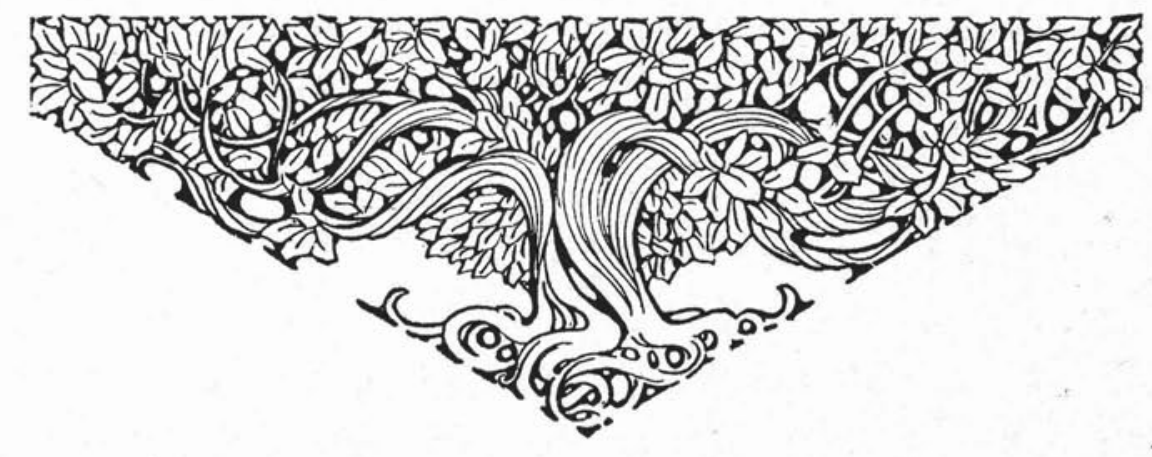

